¿Que es parol ti la educación?

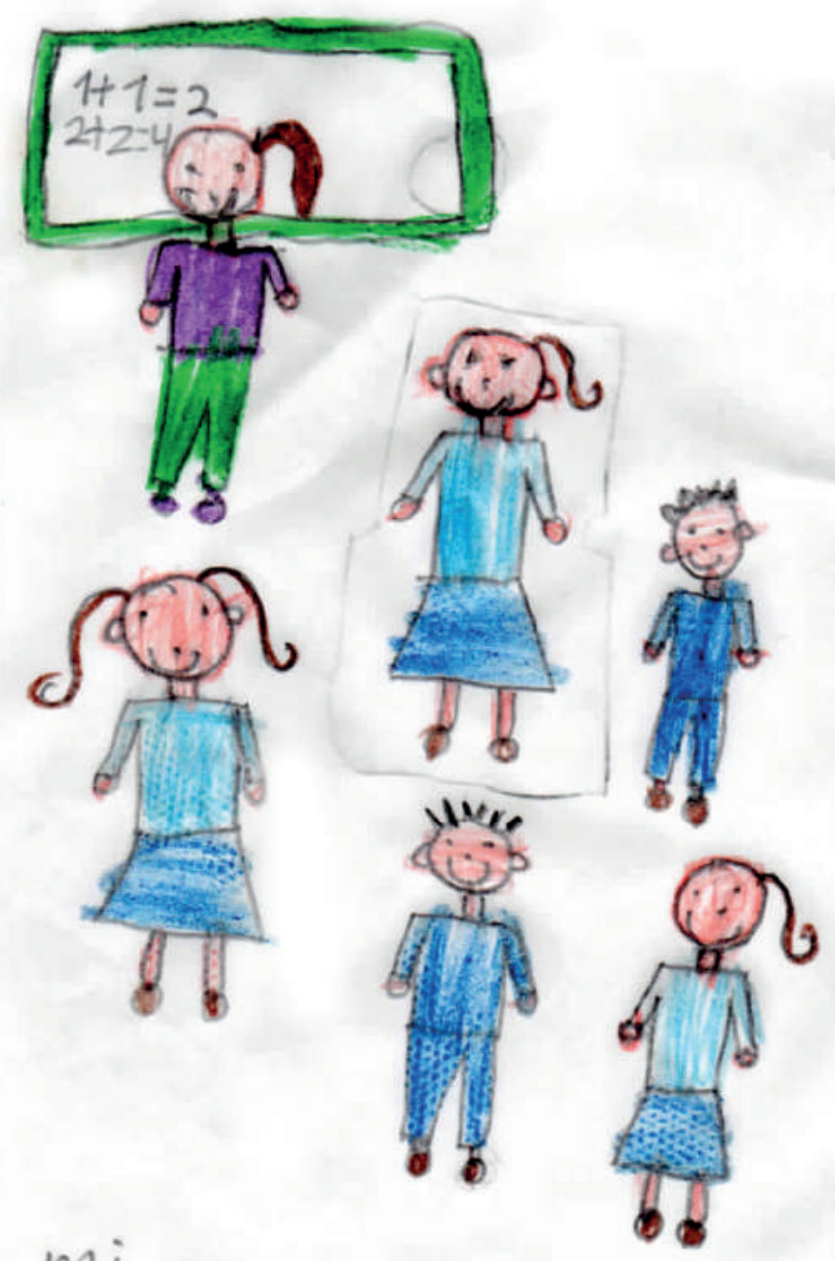

Para mi que es ser edvado es hacerle silencio a la profesora en clase

Estudios

deDerecho

UNIVERSIDAD

DE ANTIOQUIA 


\title{
Reformar la regulación de la seguridad privada en Colombia. \\ Obstáculos y retos
}

\section{Ingrid Estibaliz Sánchez Diez**}

\section{Resumen}

Este trabajo, a través de un análisis jurídico de carácter doctrinaly hermenéutico, pretende aportar una propuesta que sirva de sustento a las labores de confección de un nuevo marco normativo para el sector de la seguridad privada en Colombia.

Lasrecomendaciones se formulan tomando en consideración, ademásdelasfortalezasydeficiencias delaregulación vigente, las razones por las que, a pesar del consenso en el reconocimiento de esa necesidad, en Colombia no se ha aprobado una nueva ley de seguridad privada hasta el momento y las cuestiones respecto a las cuales el legislador debe reflexionar y adoptar una decisión previa al inicio de los trabajos para lograr la confección de una regulación sistematizada y coherente.

Palabras Clave: inversión extranjera; modificación legislativa; naturaleza; prevención; seguridad privada.

\section{The reform of private security law in Colombia.}

\section{Obstacles and challenges}

\section{Abstract}

The main aim of the research carried out in this paper is to provide a proposal in order to scaffold the reforms that must be done in order to give a new legal frame for the private security realm in Colombia.

The suggestions given take into account the positive and negative features of current law. A careful assessment about the reasons that have impeded the seal of approval to a new private security law despite the consensus in its necessity is also there. Moreover, the paper considers the main aspects that must be pondered by the legislator in order to create a coherent and systematized regulation.

Keywords: foreign investment; legal reform; prevention; private security.
\end{abstract}

\section{Reformar a regulamentação da segurança privada na Colômbia.}

\section{Obstáculos e desafios}

\section{Resumo}

Este artigo visa fornecer, por meio de uma análise jurídica de caráter doutrinal e hermenêutica, uma proposta útil para apoiar o trabal ho de confecção de um novo quadro normativo para o setor da segurança privada na Colômbia. As recomendações são formuladas levando em consideração, além das fortalezas e deficiências da regulamentação vigente, as razões pelas quais na Colombia, apesar do consenso no reconhecimento dessa necessidade, ainda não foi aprovada uma nova lei de segurança privada até agora e as questões sobre as quais o legislador deve refletir e adotar uma decisão prévia ao início dos trabalhos para conseguir a confecção de uma regulamentação sistematizada e coerente.

Palavras-chave: Investimento estrangeiro; modificação legislativa; natureza; prevenção; segurança privada.

\footnotetext{
* Artículo de reflexión. Este artículo forma parte del estudio desarrollado durante la estancia de investigación postdoctoral en la Universidad de Antioquia. Un análisis normativo del sector de la seguridad privada en Colombia del que hemos obtenido las reflexiones con las que se ha confeccionado el presente trabajo.

** Doctora en Derecho por la Universidad de Salamanca, Miembro titular de FLACSO-España, España. De febrero a noviembre de 2018 realizó una estancia deinvestigación en la Universidad de Antioquia, tutorizada por el profesor Pablo Emilio Angarita Cañas, quien ha propiciado la adscripción al Grupo interdisciplinario de investigación sobre Conflictos, Violencias y Seguridad Humana, INER, de la Universidad de Antioquia (clasificado en Colciencias categoría A1). Correo electrónico: sigrid@usal.es. ORCID: 0000-0003-3114-6179
} 


\section{Reformar la regulación de la seguridad privada en Colombia. Obstáculos y retos ${ }^{1}$}

\section{Introducción}

Durante la segunda década del presente siglo, hemos sido testigos de cómo distintos organismos internacionales han prestado atención al ámbito privado de la seguridad desde diferentes perspectivas. Se han interesado por analizar el fenómeno de la expansión del mercado de la seguridad privada y se han propuesto identificar las consecuencias que pueden derivarse de ello.

Las ópticas con las que enfocan los servicios privados de seguridad van desde la explicita preocupación que expresaba el Programa de las Naciones Unidas para el Desarrollo (PNUD) (2013, p.150) acerca de la posibilidad de que determinados servicios de seguridad privada muten hacia la configuración de auténticos ejércitos privados, hasta el velado temor evidenciado por instituciones como el Centro de Ginebra para el Control Democrático de las Fuerzas Armadas (DCAF) y el Centro Regional de las Naciones Unidas para la Paz, el Desarme y el Desarrollo en América Latina y el Caribe (UNLIREC) cuando, estimando que muchos Estados no disponen de un marco legal capaz de hacer frente a las conductas inadecuadas de las empresas del sector, ofrecen guías legislativas para orientarles sobre la regulación de la seguridad privada (DCAF, 2016) o encargan el análisis de repuestas jurídicas con el objeto de contribuir a las labores del Grupo de Trabajo de las Naciones Unidas para una posible Convención sobre las Empresas Militares y de Seguridad Privada (UNLIREC, 2011).

En Colombia, se reaviva el debate acerca de la regulación del sector a raíz de dos circunstancias que coinciden en el año 2016:

1 Este artículo de reflexión forma parte del estudio desarrollado durante la estancia de investigación postdoctoral en la Universidad de Antioquia. Un análisis normativo del sector de la seguridad privada en Colombia del que hemos obtenido las reflexiones con las que se ha confeccionado el presente trabajo. 
El archivo de la propuesta de reforma del Estatuto de Vigilancia y Seguridad Privada, con mayores posibilidades de ser aprobada entre todas aquellas que habían sido tramitadas hasta ese momento por el Congreso de la República. ${ }^{2}$

La inclusión de varias referencias a la necesidad de reformar la regulación del sector de la vigilancia y la seguridad privada en el "Acuerdo final para la terminación del conflicto y la construcción de una paz estable y duradera".

El interés internacional e interno para lograr un marco normativo que garantice una dimensión privada de la seguridad defensora de los derechos y libertades fundamentales de todos los ciudadanos y en todo el territorio, contrarrestando la desconfianza de quienes estiman que se trata de una actividad potencialmente dañina, nos empuja a afrontar el análisis de la regulación vigente en Colombia con la finalidad de identificar los motivos vinculados a la propia arquitectura normativa que harían aconsejable su reforma.

De este modo, en el contexto de la estancia de investigación postdoctoral en la Universidad de Antioquia, afrontamos el estudio de la regulación que rige el sector de la seguridad privada en Colombia indagando acerca del modo en el que se elaboran estas normas y quiénes son sus autores, los elementos que definen el ámbito de la seguridad privada en Colombia y el papel que se atribuye al órgano de control público de la actividad (la Superintendencia de Vigilancia y Seguridad Privada).

Las conclusiones obtenidas del análisis hermenéutico de normas y jurisprudencia nos llevan a estimar que hay argumentos que justifican la asunción de la labor de confección de un nuevo diseño normativo para la seguridad privada en Colombia.

Siendo el principal (por estructural), que el marco jurídico actual lo constituye una amalgama de disposiciones normativas que se enmiendan y se corrigen sin respeto a la jerarquía normativa, configurando un complejo compendio en el que en las mismas disposiciones se mezclan artículos que establecen criterios y conceptos generales con otros que recogen la regulación detallada de elementos accesorios, estimamos que el mecanismo que mayores disfunciones introduce

2 Estamos haciendo referencia al Proyecto de Ley 195/2016 C, por la cual se regula el sector de vigilancia y seguridad privada en Colombia y se dictan otras disposiciones. Texto que logró un importante consenso en el Senado y vio abortada su gestación cuando quedaban escasos trámites para su aprobación.

3 Apartado 3.4 del punto 3 denominado "Fin del conflicto". El texto del Acuerdo se refiere al sector de la vigilancia y la seguridad privada en el apartado dedicado a las garantías de seguridad y lucha contra las organizaciones y conductas criminales responsables de homicidios y masacres. 
en el sistema -y, por lo tanto, en el funcionamiento del sector- es que aspectos esenciales de la regulación estén contenidos en disposiciones que no son leyes ni reglamentos, sino resoluciones de un órgano perteneciente a la rama ejecutiva del poder público (la Superintendencia de Vigilancia y Seguridad Privada) que carece de capacidad normativa.

El mero hecho de que disposiciones esenciales para la configuración del sistema sancionador no se incluyan -o apenas aparezcan esbozadas- en la norma de mayor rango (el Estatuto de Vigilancia y Seguridad Privada) y que se incorporen a la regulación a través de la vigente Resolución 2946 de 2010 (disposición elaborada y emitida por la Superintendencia) ya justificaría por si solo la confección de una nueva ley, puesto que -como nos recuerda Santofimio Gamboa (2017) citando a la Corte Constitucional- las conductas sancionables "no solo deben estar descritas en una norma previa (tipicidad) sino que, además, deben tener un fundamento legal, por lo cual su definición no puede ser delegada en la autoridad administrativa" $^{4}($ p.474).

Como consecuencia de los resultados obtenidos del citado análisis jurídico, estimamos que el sector de la seguridad privada en Colombia está regulado por un corpus legal con falencias y carencias que dificultan la garantía de la seguridad jurídica.

El país no se ha dotado de una norma emanada del poder legislativo que defina el marco jurídico de la actividad y establezca los conceptos básicos. Lo que, unido a la necesidad de actualización de una norma emitida en un contexto socio político que ha evolucionado profundamente -tanto o más que la innovación tecnológica que está transformando estos servicios-, así como a la imprescindible adecuación a la compleja realidad presente del país, justifica la pertinencia de acometer los trabajos de elaboración de una nueva regulación para el sector.

Y es en el contexto de la colaboración con la tarea del legislador donde queremos situar la aportación de este trabajo; preguntándonos acerca de las razones por las que en Colombia no se ha aprobado una nueva ley de seguridad privada pretendiendo encontrar las respuestas que orienten al regulador en la adopción de las estrategias precisas para la superación de los obstáculos identificados. Nuestro objetivo incluye, asimismo, establecer cuáles son los retos que el análisis normativo nos ha llevado a considerar que el legislador debe afrontar de forma prioritaria para la elaboración de una arquitectura jurídica caracterizada por la coherencia interna y con capacidad para contribuir al adecuado funcionamiento del sector.

De este modo, proponemos una ruta cuyo arranque será la identificación y análisis de los motivos que han impedido la promulgación de una ley de seguri-

4 Reflexión inserta en el capítulo dedicado al procedimiento administrativo sancionador en el que analiza la Sentencia de la Corte Constitucional C 125 de 2003. 
dad privada para, alertando al legislador de que habrá primero de superar unos obstáculos mantenidos durante más de dos décadas, ofrecerle una guía cimentada en las tres materias esenciales acerca de las cuales debería adoptar una decisión (determinación de la naturaleza, enfoque preventivo o disuasorio y lucha contra la informalidad). Definición de postura que será determinante para la configuración de aspectos tan relevantes como el modelo normativo, la relación con la seguridad pública, las actividades y servicios considerados propios del sector, la formación que deben recibir sus operadores y para la consecución de un sector reputado y profesional.

El trabajo realizado en estas investigaciones tiene un carácter esencialmente doctrinal y hermenéutico. El conocimiento obtenido y las conclusiones a las que se ha llegado son consecuencia de la labor de estudio, análisis e interpretación de las normas y la jurisprudencia que regulan las materias objeto de atención del trabajo, así como la aproximación, consideración e incorporación de las reflexiones realizadas por otros juristas.

Sin embargo, para la elaboración del estudio contenido en este artículo hemos considerado necesario introducir la visión de profesionales del sector que no es posible localizar en soportes documentales con el preceptivo rigor académico.

Así, sin ánimo de ser exhaustivos -y conscientes de la imposibilidad de que un trabajo de las características del que presentamos tenga la capacidad de transmitir el pensamiento mayoritario de todos los que están implicados en la configuración, gestión y provisión de la seguridad privada en Colombia-, hemos recabado las opiniones -que estimamos representativas- de funcionarios técnicos que han desempeñado el cargo de Superintendente de Vigilancia y Seguridad Privada en distintos momentos, de los miembros del asociacionismo gremial, del ámbito empresarial y de la formación del sector, de docentes e investigadores universitarios y de participantes en el proceso legislativo.

Creemos necesario en este punto advertir que, aunque para el análisis normativo del sector (aquel del que se derivan las conclusiones justificantes de la necesidad de reformar la regulación de la seguridad privada en Colombia) se ha recurrido a la técnica del estudio comparado. En este artículo consideramos preciso eludir en lo posible las referencias a la legislación española (escogida por las conexiones jurídicas de carácter histórico existente entre ambos países y la evolución paralela que las actividades, objeto de estudio, han seguido en ellos) ${ }^{5}$.

5 La selección de la normativa española como referente legislativo internacional se realizó, además de por las razones expuestas y por la calidad legislativa que se le reconoce (Torrente Robles, 2016), por las conclusiones extraídas de la aproximación a las regulaciones que podemos encontrar en otros países de América Latina y el Caribe. Especialmente en lo que se refiere a Centro América y a los países fronterizos del subcontinente Colombia es un referente en esta materia. Como bien advierte el informe efectuado por UNLIREC (2011) son pocos los países que en la fecha del análisis habían implantado mecanismos y medidas regulatorias integrales y adecuadas, siendo Colombia de los 
La configuración sociopolítica y jurídica de Colombia en la actualidad determina una realidad securitaria tan específica que obliga a una reflexión de origen que debe realizarse exclusivamente en clave nacional.

Analizar cuáles son los obstáculos que ha interpuesto la evolución histórica y la interacción de los actores nacionales sin la interferencia de estimar factores que pueden haber sido protagonistas en otros países del entorno geográfico o cultural, y animar al legislador a que busque respuestas propias y acordes a las características y necesidades actuales del país, es la que estimamos puede ser la orientación adecuada de este trabajo.

\section{Los obstáculos}

En los más de 20 años que han transcurrido desde que fue aprobado el Decreto Ley 356 de 1994, el vigente Estatuto de Vigilancia y Seguridad Privada, se han presentado distintos proyectos de ley con el objeto de dotar al sector de una regulación elaborada en el seno del poder legislativo con capacidad para superar las lagunas y deficiencias identificadas en el marco normativo vigente, incluyendo para ello las aportaciones de los profesionales. Ninguno de ellos ha sido aprobado.

Esta imposibilidad genera la curiosidad del observador, que se pregunta acerca de qué es lo que la motiva.

Al averiguarlo vamos a interrogarnos acerca de cuáles son las razones por las que Colombia no ha dotado al sector de la seguridad privada de una regulación que contribuya a su adecuación a la vigente situación del país, a su actualización operativa y técnica y a su modernización profesional.

\section{1. Hipótesis que surgen de una aproximación inicial.}

\section{- La vinculación de la seguridad con la rama ejecutiva del Estado.}

Podríamos caer en la tentación de simplificar y achacar las causas a una concepción de la seguridad que la vincularía esencialmente a la rama ejecutiva. Una visión que consigue asentarse hasta el punto de convencer al legislativo de la necesidad de delegar su misión de dibujar el marco normativo de todo lo que atañe a la seguridad en manos del ejecutivo.

escasos que obtiene una valoración positiva con respecto a la evaluación de la adecuación de los contenidos de su normativa a los principios que propugna la entidad en la mayoría de los aspectos analizados. 
No faltan los indicios de que esto podría ser así. Al acudir a las leyes habilitantes ${ }^{6}$, tanto a la promulgada en 1989 como a la dictada en 1993, observamos que no solo se faculta al Presidente de la República, correspondiente para expedir el estatuto de vigilancia privada y el estatuto de vigilancia y seguridad privada respectivamente, sino que en ellas también se le capacita para reformar los estatutos y el régimen de prestaciones del personal de Oficiales, Suboficiales, Agentes Civiles del Ministerio de Defensa, las Fuerzas Militares y la Policía Nacional (en la Ley 66 de 1989) y para regular sobre armas, municiones y explosivos (en el caso de la ley 61 de 1993). En ambas normas, la regulación de la vigilancia y la seguridad privada está incluida en un conjunto, cuyos elementos tienen en común que afectan a la competencia estatal de procurar seguridad.

Podríamos sugerir que tales delegaciones evidencian al menos la tendencia a considerar la seguridad (y su regulación) un asunto propio de la rama ejecutiva del poder público.

Defender esta hipótesis exige enfrentar un estudio relativo a la evolución de la concepción de la seguridad en Colombia con el fin de determinar si se asume una idea de seguridad con un carácter netamente atractivo que pretenda la incorporación de los distintos ámbitos de la seguridad a la órbita de la seguridad pública y de las competencias del ejecutivo ${ }^{7}$. Y, a su vez, un acercamiento al modo en el que en este país se articula la relación entre la rama ejecutiva y la legislativa del poder público para -guiados por las reflexiones de Urrego Ortiz y Quinche Ramírez (2008, p.64)- tratar de dilucidar si la atribución a la rama ejecutiva de la capacidad de dictar normas con rango de ley de manera repetida sobre una misma materia la cual supone concederle el poder de decisión total respecto a su configuración.

No siendo estos los objetos del actual trabajo, sí encontramos argumentos que, sin entrar a profundizar en la cuestión, nos llevan a cuestionar la validez del supuesto de partida.

Si bien es cierto que en 1993 el Congreso delega en el Presidente de la República la facultad de dictar el Estatuto de Vigilancia y Seguridad Privada ${ }^{8}$, así como otra serie de cuestiones que conectan con el núcleo esencial de la seguridad ${ }^{9}$, el

6 Aquellas por las que -en virtud de lo dispuesto en el artículo 150.10 de la Constitución Política, y en palabras de Urrego Ortiz y Quinche Ramírez (2008, p. 57)- "el Congreso, titular de la facultad legislativa, se despoje de ella para habilitar al Presidente de la República" a expedir normas con fuerza de ley cuando, como nos recuerda Libardo Rodríguez (2017, p. 52), "la necesidad lo exija o la conveniencia pública lo aconseje”.

7 En una línea de investigación semejante a la desarrollada por la autora en su trabajo dedicado a la evolución de la concepción de la seguridad en España ("Sánchez Diez", 2016, p. 286).

8 A través de la Ley 61, de 12 de agostos de 1993, por la cual se reviste al Presidente de la República de facultades extraordinarias para dictar normas sobre armas, municiones y explosivos, y para reglamentar la vigilancia y la seguridad privada.

9 Tales como la creación del órgano que controla el ámbito de la seguridad privada, la Superintendencia de Vigilancia y Seguridad Privada. Ley 62, de 12 de agosto de 1993, por la cual se expiden normas sobre la Policía Nacional, se crea 
contexto político y sociológico podía justificar la cesión de la función legislativa por las razones de necesidad y urgencia que exige esta fórmula. Es decir, el Congreso no renuncia a su facultad en relación con la seguridad por considerarse discapacitado para tratar esta materia, sino porque la situación de violencia y proliferación de grupos armados de carácter ilegal, que afectaban a la consecución y mantenimiento del monopolio de la fuerza por parte del Estado, hacía necesaria la emisión urgente de una norma con capacidad de ordenar y regular el sector de la seguridad privada ${ }^{10}$.

En el contexto descrito, esta regulación debía tener por objeto aprovechar las capacidades de los operadores privados cuya actuación se sujeta a la Constitución y a lo dispuesto en el ordenamiento jurídico y, a su vez, proscribir los servicios irregulares constituidos con finalidades consideradas ilegítimas por la arquitectura normativa colombiana.

La premura con la que la norma era solicitada resultaba incompatible con los plazos que se manejan en el Congreso, y más en un tiempo en el que los senadores y congresistas estaban entregados a la ardua tarea de desarrollar lo establecido en la Constitución Política aprobada en $1991^{11}$.

El Congreso delegó en el ejecutivo la emisión de la regulación de la seguridad privada (y de otras materias securitarias) por razones de necesidad (la preceptiva erradicación de los grupos armados de autodefensa y ataque constituidos al margen o en los límites de la ley) y de urgencia (en un momento en el que se requería una respuesta rápida que el legislativo no estaba en disposición de ofrecer).

Con posterioridad han sido varias las oportunidades en las que, impulsados por distintos senadores, se han presentado proyectos de ley destinados a modificar y actualizar el Estatuto de Vigilancia y Seguridad Privada. Lo que demuestra la voluntad del Congreso de la República de desempeñar su función legislativa, también en lo que concierne al ámbito de la seguridad asumido por operadores privados.

un establecimiento público de seguridad social y bienestar para la Policía Nacional, se crea la Superintendencia de Vigilancia y Seguridad Privada y se reviste de facultades extraordinarias al Presidente de la República.

10 A la situación de violencia que describe González González (2014, p. 379 y 396) en la Colombia de la década de los años ochenta y principios de los años noventa hay que añadir que a la sombra de las actividades legítimas de seguridad privada comenzaron a surgir prácticas que vincularon a determinados servicios con el paramilitarismo y se usaron algunas empresas como fachada para la creación de lo que más tarde se denominaron las autodefensas (algunas de las cuales surgieron con la finalidad de constituirse como organizaciones vecinales de autoprotección que fueron pervertidas y manipuladas por los intereses del narcotráfico). En las entrevistas realizadas a los profesionales se refirieron a estas circunstancias Iván Mauricio Gaitán Gómez (comunicación personal, 9 de mayo, 2017), Andrés Macías Tolosa (comunicación personal, 11 de mayo, 2017), Sandra Carvajal Villamizar (comunicación personal, 5 de junio, 2017), Agustín Jiménez Cuello (comunicación personal, 6 de junio, 2017), el Mayor (r) Germán Duarte Vargas (comunicación personal, 21 de junio, 2017), el Coronel (r) Luis Enrique La Rotta Bautista (comunicación personal, 21 de julio, 2017).

11 Como señala Sarabia Better (2003, p. 108), el poder legislativo se fijó como prioridad la aprobación de una reforma política que diera desarrollo a las recientes normas constitucionales. 


\section{- La polarización política y la dificultad de llegar a acuerdos en el legislativo.}

Ninguno de los textos presentados ${ }^{12}$ ha logrado ser aprobado y entrar en vigor. El último de los intentos realizados hasta la fecha, el Proyecto de Ley 195/2016C, vio abortada su gestación cuando quedaban escasos pasos para la culminación de su tramitación.

El texto tuvo un largo recorrido que se inició en 2014 de la mano del Senador Óscar Mauricio Lizcano Arango (representante del Partido de la U) y concluyó con su archivo el 7 de junio de 2016. Para esa fecha el documento había sido intensamente modificado y era el resultado de un amplio consenso en la consecución del cuál habían sido protagonistas representantes de partidos tan alejados ideológicamente como el Partido Conservador Colombiano, el Partido de la U, el Polo Democrático y el Partido Liberal. ${ }^{13}$

La segunda de las hipótesis a las que había recurrido el observador externo, la fuerte polarización política que haría imposible llegar a un acuerdo acerca de las líneas maestras que habrían de definir el marco de la seguridad privada, no encuentra sustento ante la evidencia de que, al menos en este último caso, los miembros del poder legislativo sí consiguieron elaborar un texto que contaba con el apoyo de la mayoría del Senado.

\section{- La consideración de la seguridad privada como factor generador de riesgo.}

A las dos consideraciones anteriores podemos añadir la preocupación que todavía se transluce en la sociedad colombiana por fenómenos protagonizados por individuos o empresas que han desvirtuado la actividad, incrementando la ya existente desconfianza de ciertos sectores hacia la seguridad privada.

Son notorias las advertencias acerca de la seguridad privada que encontramos en documentos internacionales (PNUD, 2013, p.150), así como en trabajos de investigación (Angarita, 2010, p.337). En éstos se evidencia el temor de que determinados servicios de seguridad privada muten hasta la configuración de auténticos ejércitos privados. Servicios tales como los denominados especiales y comunitarios que, contenidos en los capítulos V y VI del Título II del Estatuto de

12 Ni el tramitado en 2008 con el título de Proyecto de Ley 188/Senado, ni el presentado por los senadores Juan Lozano Ramírez y Carlos Emiro Barriga en 2013, ni el denominado Proyecto de Ley 195/2016C, por citar algunos de los últimos y más representativos ejemplos.

13 Suscribieron el acuerdo los senadores Nidia Marcela Osorio Salgado del Partido Conservador Colombiano, Oscar Mauricio Lizcano Arango, del Partido de la U, Iván Cepeda Castro del Polo Democrático, Juan Manuel Galán Pachón y Luis Fernando Velasco Chaves, ambos del Partido Liberal. (Prensa S. Mauricio Lizcano, 2015, recuperado de http:// www.senado.gov.co/historia/item/22397-aprobados-en-primer-debate-proyectos-que-regulan-seguridad-privaday-prohiben-cigarrillos-electronicos-a-menores) 
Vigilancia y Seguridad Privada, son desarrollados por el Decreto 2974 de 16 de diciembre de 1997. Modalidades de la actividad que alertaron a quienes, desde muy temprano, advirtieron acerca de la posibilidad de que la regulación de éstas facultara a los ciudadanos a organizarse en grupos armados. Algo que, según el representante de la Comisión Colombiana de Juristas, solo conseguiría involucrar a más civiles en el conflicto armado e incidiría en la proliferación de grupos paramilitares $^{14}$.

Lo llamativo es que, respecto a la preocupación y el temor, lo que cabría esperar no sería precisamente la inactividad legislativa, sino un esfuerzo conducente a consensuar una nueva norma que, superando las falencias y desactualizaciones advertidas en la vigente, definiera adecuadamente el marco normativo de la actividad reduciendo los ámbitos de indefinición y los márgenes de desarrollo de actividades no deseadas.

Tal era uno de los propósitos principales de los senadores que lideraron el acuerdo de 2015; confeccionar un Estatuto que fijara los límites que no se deben traspasar para evitar el uso abusivo de las funciones atribuidas (Jiménez, 2017).

Siendo que entrega, en espacios físicos determinados, el control de armas a personas que no pertenecen a la función pública y que otorga la capacidad de ejercer actividades preventivas y disuasorias de carácter securitario a quienes no cuentan con la consideración de autoridad, los miembros del legislativo que participaron en la elaboración y tramitación del Proyecto de Ley 195/2016C entendieron la necesidad de regular el sector de la seguridad privada con base en el respeto y garantía de los derechos humanos y del derecho internacional humanitario.

Sin embargo, a pesar del acuerdo entre los sectores mayoritarios que controlan el legislativo, el proyecto no llegó a ser aprobado como Ley.

Para determinar por qué el Proyecto de Ley 195/2016C fue finalmente archivado y las razones por las que Colombia no cuenta con una nueva ley de seguridad privada, vamos a acudir a una fuente especialmente cualificada; los profesionales y estudiosos del sector.

\subsection{Razones que se aducen desde el ámbito profesional}

Julio Cesar Vásquez (2017), quien desempeñó el cargo de Superintendente de Vigilancia y Seguridad Privada en el período de 1998-2002, nos ofrece una lista de 5 motivos, casi todos los cuales han sido alegados por alguno de los demás consultados.

14 Es en estos términos en los que se expresa el aludido al intervenir en el proceso que resuelve sobre la demanda de inconstitucionalidad acerca de la que se pronuncia la sentencia C 572 de 1997. 
1. La primera razón a la que alude es a la inestabilidad de los funcionarios que asumen la responsabilidad de Superintendente de Vigilancia y Seguridad Privada. Lo que, a su entender, se traduce en una falta notable de iniciativa técnica en la génesis y el impulso de la propuesta de una nueva regulación.

Aunque la iniciativa legislativa no precisa de la implicación de la entidad de control para el desarrollo de una propuesta, entendemos que la tarea de elaboración y generación de consensos puede verse dificultada por la interinidad del máximo responsable técnico en la materia. ${ }^{15}$

El ejemplo más claro de que este factor puede influir en la agilidad y eficiencia de los trámites legislativos lo tenemos en lo ocurrido durante el año 2017; Carlos Mayorga dejó el cargo en febrero de 2017 habiendo presentado un borrador de proyecto de Decreto Ley para la modificación del Estatuto de Vigilancia y Seguridad Privada vía Fast Track ${ }^{16}$. Cerrada la vía de tramitación de esta materia a través de este procedimiento, en virtud de la sentencia de la Corte Constitucional 160 de $2017^{17}$, el nuevo Superintendente de Vigilancia y Seguridad Privada -Fernando Martínez Bravo- enfrenta, tras su toma de posesión en abril de 2017, el encargo del ejecutivo de proponer un nuevo texto para el impulso de la modificación a través de una ley ordinaria.

Obviamente, que hubiera sido la misma persona -con una visión y proyecto asentado durante su ejercicio previo- la que estuviera al frente de la entidad hubiera contribuido a que el encargo fuera cumplido con mayor celeridad y eficacia.

2. La segunda de las causas la sitúa en las dos ramas del poder del Estado a las que hemos venido aludiendo: considera que, por una parte, los distintos gobiernos no han tenido un auténtico interés por propiciar y facilitar la actualización legislativa en este campo y que, por otra, en ocasiones los proyectos han sido presentados por senadores cuya intención principal era la de acercarse electoralmente al sector, personalizando sus propuestas hasta el punto de hacer difícil la adhesión de otros congresistas.

15 Repasando la lista de personas que han desempeñado el cargo en los últimos 20 años (desde 1998 hasta 2017), advertimos que únicamente el señor Vásquez ejerció su responsabilidad por un período cercano a los cinco, siendo lo más común que los Superintendentes lo hayan sido por plazos no superiores a los dos años. Así, el Sr. Felipe Muñoz Gómez ejerció la responsabilidad desde 2006 a enero de 2009, el Sr. Felipe Murgueitio Sicard desde diciembre de 2009 a agosto de 2012, D. Fernando Lozano Moreno de marzo de 2013 a septiembre de 2014 y D. Carlos Alfonso Mayorga Prieto de mayo de 2015 a febrero de 2017.

Puesto que consideraba que la inclusión de algunas referencias relativas al sector de la seguridad privada en el punto 3.4 de los Acuerdos de la Habana permitía que la reforma del Estatuto fuera acogida por el trámite especial que establece el acto legislativo 01 de 2016. 
Destaca que las fechas de presentación de los proyectos impulsados por el Gobierno con frecuencia han sido cercanas a los períodos electorales ${ }^{18}$ o que su presentación ha coincidido con la tramitación de otros proyectos de ley muy importantes para el ejecutivo (en los que parecía tener un mayor interés).

3. En tercer lugar, alude a la dispersión gremial del sector y a la existencia de intereses enfrentados en el seno de este.

El Sr. Vásquez (2017), quién al dejar su responsabilidad al frente de la Superintendencia de Vigilancia y Seguridad Privada fue durante casi 5 años vicepresidente para el Sector de Seguridad Privada en FENALCO (Federación Nacional de Comerciantes), estima que, actualmente, no hay unidad de acción en el sector para trabajar sobre una propuesta legislativa que incluya los grandes temas que preocupan a los profesionales.

Por su parte, representantes gremiales como el Sr. Medina (2017) y el Mayor Duarte (2017) citan también -aunque inciden menos en la cuestión- la vigencia de intereses difícilmente conciliables y la lucha por la prevalencia de cada ámbito del sector sobre los demás que lo integran. Ambos se refieren expresamente a lo determinante que resulta el tamaño y el ámbito de protección en el que se desempeñan las empresas para definir cuáles son sus retos y problemas principales. ${ }^{19}$

Incluso desde el ámbito académico, Julio Cesar González (2017), analizando las causas por las que se llegó al archivo del Proyecto 195/2016C, se lamenta de que, por parte del sector, fue más evidente la voluntad de defensa de intereses puntuales que la de aportar efectivamente al desarrollo y evolución de la seguridad privada.

4. En último lugar hemos puesto el asunto recurrente, la causa citada por todos los entrevistados, aquella que se ha esgrimido en prensa y por parte

18 Avalaría esta teoría la afirmación del Superintendente Martínez Bravo respecto al compromiso del Gobierno de Juan Manuel Santos de aprobar un nuevo Estatuto de Vigilancia y Seguridad Privada, a través de una ley ordinaria, antes del final del período legislativo en curso (comunicación personal, 6 de julio, 2017). Toda vez que las elecciones legislativas se celebraron el 11 de marzo de 2018, el proyecto no contaba con más de 7 meses para su tramitación y aprobación. Plazo que se evidenció como insuficiente al constituirse el Congreso de la República el 20 de julio de 2018 sin que Colombia se hubiera dotado de una nueva Ley de seguridad privada.

Así, según ANDEVIP, las empresas pequeñas (aquellas que disponen de hasta 300 vigilantes) se dedican especialmente a desempeñar labores de vigilancia en el ámbito residencial, las medianas (hasta 2.000 hombres) se centran en el ámbito comercial, educativo y del sector servicios (como seguridad de acceso en aeropuertos) y las grandes se orientan a los ámbitos financiero, industrial y empresarial de carácter multinacional. De este modo, las empresas grandes son las que requieren un respaldo financiero de mayor volumen al estar sometidas a un régimen de pagos diferido y a la necesidad de realizar fuertes inversiones en equipamiento y soluciones técnicas innovadoras que son requeridas por las características de sus clientes, mientras las pequeñas y medianas, más asentadas en el recurso humano, aunque no requieran tanta financiación son más vulnerables a los avatares del mercado y su capacidad de obtener financiación es muy limitada (Medina Ovalle, comunicación personal, 20 de junio, 2017). 
de los cauces oficiales, como razón última del archivo del Proyecto de Ley 195/2016C: la controversia respecto a la admisibilidad de la presencia de inversión extranjera en la seguridad privada colombiana.

Tras referirnos brevemente a las tres primeras, vamos a dedicar un apartado específico al análisis del problema de la inversión extranjera para tratar de comprender por qué es tan determinante para lograr, incluso, el archivo de un proyecto a las puertas de su aprobación.

\section{- La adecuación de admitir la presencia y la inversión extranjera en el sector de la seguridad privada en Colombia.}

Esta ha sido una de las principales razones que se recogen en los artículos publicados en la prensa de Colombia para justificar el archivo de un proyecto de ley que estaba próximo a finalizar su tramitación y ser aprobado ${ }^{20}$.

El Gobierno, con el Ministro de Defensa y el Superintendente de Vigilancia y Seguridad Privada como agentes directamente implicados en la materia, se opuso al proyecto por considerar que el texto, tal como se aprobó en el Senado, discriminaba la inversión extranjera y violaba los derechos adquiridos de los inversores ya asentados en Colombia ${ }^{21}$.

Lo paradójico es que se esgrime este argumento mientras la regulación vigente, el Estatuto de Vigilancia y Seguridad Privada aprobado en 1994, y la jurisprudencia de la Corte Constitucional plasmada en la sentencia C123/11 establecen que los socios de las empresas de vigilancia y seguridad privada deberán ser personas naturales de nacionalidad colombiana ${ }^{22}$ y se limita la participación de los socios o capital extranjero que se hubieran constituido en el sector antes de la entrada en vigor del Decreto 356, al indicarse en éste que no podrán aumentar su participación ${ }^{23}$. Lo que, indirectamente, dificultaría notablemente la entrada y permanencia de la inversión extranjera en el sector.

20 (2016, 04 de junio). El controvertido proyecto para regular la vigilancia y seguridad privada. Revista Semana. Recuperado de http://www.semana.com/nacion/articulo/ley-de-vigilancia-seria-hundida-en-congreso/476324.

(2016, 07 de junio). Cámara archiva proyecto de ley para regular vigilancia privada. El Tiempo. Recuperado de http:// www.eltiempo.com/archivo/documento/CMS-16613633.

(2016, 07 de junio). Se hundió proyecto de ley que buscaba regular la seguridad privada en Colombia. El País. com.co. Recuperado de http://www.elpais.com.co/colombia/se-hundio-proyecto-de-ley-que-buscaba-regular-laseguridad-privada-en.html.

21 Carlos Mayorga, quién desempeñaba el cargo de Superintendente de Vigilancia y Seguridad Privada en la fecha de archivo del proyecto, se expresa en este sentido, aunque afirma que no es éste el único tema que desaconsejaba la aprobación (comunicación personal, 3 de mayo, 2017).

22 Artículo 12 del Decreto Ley 356, de 11 de febrero de 1994, por el cuál se expide el Estatuto de Vigilancia y Seguridad Privada.

23 Parágrafo del artículo 12 del Decreto Ley 356, de 11 de febrero de 1994, por el cuál se expide el Estatuto de Vigilancia y Seguridad Privada. 
Sin embargo, tal y como señalan desde ANDEVIP (Medina Ovalle, 2017), en la actualidad hay en Colombia unas 950 empresas de vigilancia y seguridad privada, de las cuales, sólo las 4 que tienen carácter multinacional ${ }^{24}$ concentran el $45 \%$ de la facturación.

Lo cual es posible a causa de que la redacción de la norma no prohíbe expresamente la aportación de capitales extranjeros y que la citada sentencia de la Corte Constitucional tampoco se pronuncia claramente sobre ellos, sino que se refiere exclusivamente al artículo 12 del Estatuto en el que se prescribe que los socios de las empresas de vigilancia y seguridad privada deben ser personas naturales y de nacionalidad colombiana.

El Proyecto de Ley 195/2016C se propuso clarificar la cuestión, y zanjar el debate, introduciendo un artículo 4 en el que conforme se establecía que "bajo ningún tipo societario se permitirá la inversión de capitales extranjeros en el sector de la vigilancia y seguridad privada".

A pesar de lo taxativo de la redacción no eliminaba completamente la posibilidad de la participación de capital extranjero en el sector: la prohibición se circunscribía a la prestación de servicios de vigilancia y seguridad humana, a los de capacitación y entrenamiento y a la fabricación, comercialización, instalación y arrendamiento de armas de cualquier tipo.

Lo que significa que sí hubiera sido permitido en las actividades propias de la vigilancia electrónica, el transporte de valores, las actividades de blindaje y arrendamiento de elementos blindados, las actividades de fabricación, importación, comercialización, instalación o arrendamiento de equipos destinados a la vigilancia y seguridad privada (siempre que no pudieran ser considerados como armas) y la consultoría, asesoría y estudios en vigilancia y seguridad privada.

Obviamente no se trataba de una buena noticia para las empresas participadas por capital extranjero ${ }^{25}$. El proyecto limitaba su cooperación en el mercado y lo hacía negándoles la posibilidad de asumir servicios propios de la vigilancia y seguridad humana en un sector caracterizado por desempeñarse principalmente en ese ambiente ${ }^{26}$.

24 Prosegur Vigilancia y Seguridad Privada, G4s Secure Solutions Colombia S.A., Securitas Colombia S.A. y la empresa de transporte de valores Brinks de Colombia S.A.

http://www.fedeseguridad.org/sitio/fedeseguridad/c_asociadas.html

25 Debemos señalar que esta disposición únicamente afectaría a las empresas con socios o capital extranjero constituidas durante la vigencia del Estatuto de 1994. El parágrafo que incorpora el artículo 4 establecía que serían respetados los derechos adquiridos de las personas jurídicas con socio o capital extranjero antes de la entrada en vigencia del Decreto Ley 356 de 1994.

26 Según la información aportada por ANDEVIP (Medina Ovalle, comunicación personal, 20 de junio, 2017): el 70\% de las empresas que se dedican a la seguridad privada en Colombia desempeñan sus funciones en el ámbito de la vigilancia de base humana. 
Además, la oportunidad de adaptarse a los ámbitos permitidos, reorientando su oferta a la vigilancia electrónica, el transporte de valores, el blindaje, la facilitación de equipos o la realización de consultorías, asesorías y estudios, debería realizarse en un plazo de tiempo muy limitado. El parágrafo del artículo 11 -dedicado a la vigencia de la licencia de funcionamiento- establecía que las empresas con socios o capital extranjero que en la actualidad cuenten con licencia para las actividades que la nueva norma les proscribe no podrían renovar su licencia para dichas actividades (lo que, teniendo en cuenta que la norma vigente las otorga por un plazo máximo de 5 años, hubiera significado que, en ningún caso, dispondrían de más de ese tiempo para la adaptación).

Aparentemente se trata de un problema económico vinculado al proteccionismo del eslabón nacional de la cadena.

Sin embargo, el argumento principal que se esgrime para negar la posibilidad es de carácter jurídico.

Consultado acerca de cómo se había llegado a la conclusión de que el sector debería estar regulado con base en un sistema dual (en el que se diferencia entre actividades y esto constituye el criterio esencial para permitir o no la inversión extranjera) Agustín Jiménez Cuello (2017) -aludiendo a los trabajos de consecución del acuerdo- se refiere, expresamente, a la defensa de la empresa nacional sin aportar argumentos que justifiquen la discriminación entre los dos grupos de actividades. Sí insiste, sin entrar en detalles, en que la determinación de que hay servicios que deben ser prestados por empresas nacionales en exclusiva tiene anclaje jurisprudencial.

Está haciendo referencia a la sentencia C 123/11 de la Corte Constitucional.

\section{- El aspecto jurídico.}

La revisión de la sentencia nos sirve de introducción para afrontar el auténtico problema que constituye la base jurídica del asunto de la admisibilidad de la inversión y participación extranjera en el sector de la seguridad privada; la naturaleza que se atribuye a la actividad.

Aunque, como ya hemos advertido, la sentencia C $123 / 11$ no se refiere expresamente al tema de la inversión extranjera, sino que se centra en el análisis de la constitucionalidad de los artículos del Decreto 356 de 2014 que exigen la nacionalidad colombiana a personas naturales que se constituyan como socios de las empresas de vigilancia y seguridad privada con base en la vulneración del principio de igualdad, los argumentos que aporta para declarar la exequibilidad de los citados artículos, son a los que, desde su dictamen, recurren los defensores de la imposibilidad de aceptar la inversión extranjera en el sector.

La propia Corte Constitucional, en el inicio del análisis, se centra en la naturaleza que se atribuye a la seguridad (con carácter general). Al igual que hace en 
sentencias precedentes ${ }^{27}$, recurre a los artículos 2 y 365 de la Constitución Política de 1991 para determinar que la seguridad es un servicio público y que, como tal, su prestación podrá ser encomendada a los particulares, reservándose en manos del Estado la regulación, el control y la vigilancia de dicho servicio.

Por lo tanto, insiste nuevamente en la consideración de la seguridad privada como parte integrante de la única seguridad que se concibe en Colombia. Es decir, como seguridad pública cuya prestación recae en el actor privado por delegación del Estado y que se diferencia de la que presta éste a través de sus operadores públicos por las limitaciones funcionales y materiales a las que está sometida y por su finalidad eminentemente disuasoria ${ }^{28}$.

En el punto 8 del apartado correspondiente a las Consideraciones y Fundamentos, la Corte destaca que el ejercicio de los servicios de seguridad privada está ligado a la utilización de la fuerza, lo que involucra elevadas dosis de riesgo social. La propia sentencia circunscribe el conjunto de actividades propias del sector que considera arriesgadas: se refiere expresamente a aquellas que impliquen el manejo de armas de fuego y herramientas securitarias con capacidad de afectar a la vida o la integridad física y a la capacitación y entrenamiento, ya que vincula la formación en seguridad privada al adiestramiento en el uso de esas armas y herramientas ${ }^{29}$.

Hasta este momento, lo que hace la sentencia es limitarse a señalar los riesgos que pueden derivarse del simple manejo y uso de estos elementos, sin entrar a considerar que una parte importante de los servicios y modalidades de prestación que contempla el Decreto, no implica su participación.

En el siguiente apartado, el punto 9, donde argumenta con base en la naturaleza de la seguridad privada, su conclusión estima que supone la prestación de un servicio público que guarda estrecha relación con la garantía del orden público

27 C 572/97 y C 199/01, que cita la propia sentencia en su primera página.

28 Delimitación entre los ámbitos competenciales de los actores privados y de la fuerza pública que la normativa realiza con la misma falta de precisión que la jurisprudencia, limitándose a prescribir que los primeros no asumirán funciones reservadas en exclusiva a la segunda, en los artículos 73 y 74.2 del Estatuto de Vigilancia y Seguridad Privada, o en el artículo 40.3 de la Resolución 2946 de 29 de abril de 2010 por la cual se modifica el Régimen de Control, Inspección y Vigilancia en la Superintendencia de Vigilancia y Seguridad Privada.

La finalidad disuasoria de los servicios de seguridad privada la hayamos en lugar preeminente de los textos normativos colombianos; está recogida en los artículos que definen las acciones y servicios de vigilancia y seguridad privada, determinando que serán actividades tendentes a prevenir, disminuir y disuadir las amenazas que puedan afectar al objeto de protección (artículos 2, 73 y 74 del Decreto 356, de 11 de febrero de 1994, por el que se expide el Estatuto de Vigilancia y Seguridad Privada, artículos 1 y 2 del Decreto 2187, de 12 de octubre de 2001, por el cual se reglamenta el Estatuto de Vigilancia y Seguridad privada y los numerales 3, 4, 8 y 10 del artículo 40 de la Resolución 2946, de 29 de abril, de 2010).

29 Apartado 8.3 del punto VI. CONSIDERACIONES Y FUNDAMENTOS. Sentencia C123/11. Bogotá, D.C., 1o de marzo de 2011. 
al que define como "condiciones necesarias e imprescindibles para garantizar el goce efectivo de los derechos de todos" ${ }^{30}$

Lo que lleva, en el punto 10, a finalizar su exposición defendiendo que el tratamiento diferencial está justificado por la necesidad de protección del orden público ${ }^{31}$ y la seguridad ciudadana ${ }^{32}$, determinando que los límites que se establecen a la participación extranjera en la seguridad privada obedecen a la capacidad de esta actividad de generar riesgo social y comprometer el orden público. ${ }^{33}$

A nuestro entender, la Corte sustenta su decisión con base en dos pilares de diferente calado. Por un lado, evidencia su desconfianza hacia la posibilidad misma de que los particulares tengan acceso al manejo de elementos con evidente potencial dañino, sin presumir que su formación, capacitación y pundonor profesional va a reducir al mínimo los posibles riesgos (presunción que sí se aplica a los miembros de la Fuerza Pública a los que se entiende debidamente formados en valores y aptitudes técnicas) ${ }^{34}$.

30 La propia sentencia nos remite en esta cita literal a la Sentencia C1053 de 2003. Apartado 9, primer párrafo final, del punto VI. CONSIDERACIONES Y FUNDAMENTOS. Sentencia C123/11. Bogotá, D.C., 1ํo de marzo de 2011.

31 La propia Corte Constitucional nos remite a su jurisprudencia cuando define el orden público como "las condiciones mínimas de seguridad, tranquilidad, salubridad y moralidad que deben existir en el seno de la comunidad para garantizar el normal desarrollo de la vida en sociedad" (Sentencia SU-476/97. Bogotá, D.C., 25 de septiembre de 1997) y las "condiciones necesarias e imprescindibles para garantizar el goce efectivo de los derechos de todos" (Sentencia C1053/03. Bogotá, D.C., 11 de noviembre de 2003).

Consideramos relevante la aportación teniendo en cuenta que las normas no se han detenido en la delimitación conceptual y que el término "orden público" ha generado controversia en Colombia. Tal y como señala León Valencia en el prólogo del libro Seguridad y Justica en tiempos de paz; el concepto fue adoptado en 1963 (a raíz del discurso de Alberto Lleras Camargo en el Teatro Patria) como una noción genérica destinada a delimitar la función Policial (control del orden público) con el objeto de que evitar la participación de la fuerza pública en la actividad política. Posteriormente las expresiones análogas a "problemas de orden público" fueron utilizadas para referirse a los incidentes vinculados a la insurgencia y el conflicto armado, llegando a incluir las actividades propias de la protesta social (Ávila \&Londoño, 2017, p. 20 y 21).

32 En relación con lo anterior cabe destacar la introducción del término "seguridad ciudadana" en el texto de la sentencia. Su delimitación y distinción conceptual respecto del término orden público resulta complicada, aunque la sentencia al incluir ambas en relación coordinada parece señalar que se refieren a realidades diferentes (pues no tendría sentido que usara dos expresiones con el mismo significado de forma consecutiva en una misma frase). Según las sentencias constitucionales citadas, la atribución -en el artículo 218 de la Constitución Política de 1991- a la Policía Nacional del "mantenimiento de las condiciones necesarias para el ejercicio de los derechos y libertades públicas y para asegurar que los habitantes de Colombia convivan en paz" deberemos identificarla con la misión del mantenimiento del orden público, mientras la seguridad ciudadana conectaría con la protección de personas y bienes a la que se refiere la Constitución en su artículo 2. En este sentido se expresa Rincón Morera (2018, p. 92) al interpretar lo que significó la aprobación de la Constitución Política de 1991. Según este autor se "hizo necesario el diseño de una serie de políticas públicas que tuvieran en cuanta la necesidad de soluciones particularizadas y la conceptualización de la seguridad no únicamente en términos del orden público, sino también en correspondencia con la seguridad de la ciudadanía".

33 Apartado 10 - Conclusión- del punto VI. CONSIDERACIONES Y FUNDAMENTOS. Sentencia C123/11. Bogotá, D.C., 1ำ de marzo de 2011.

34 Con carácter general se asume que los integrantes de las Fuerzas Públicas de los estados democráticos y de derecho son actores con una identidad corporativa muy marcada, que pertenecen a cuerpos fuertemente jerarquizados y en los que adquieren especial importancia los valores y elementos simbólicos. Además, están sujetos a un régimen 
Siendo relevante, para este factor no tiene transcendencia, en principio, la nacionalidad de los socios de la empresa o la procedencia del capital que la sostiene. Más bien entronca con los lógicos cuestionamientos acerca de la efectividad de los planes educativos y los entrenamientos exigidos al personal, así como con la responsabilidad del empresario en la adecuada selección y la garantía de unas condiciones de trabajo dignas y ajustadas a las exigencias de atención, respuesta y reflejos que implica la seguridad privada. ${ }^{35}$

En el otro factor, se aproxima al asunto de la determinación de la naturaleza de la seguridad privada, insertándola de lleno en el núcleo esencial de la seguridad al estimar que estos servicios guardan estrecha relación con la garantía de las "condiciones necesarias e imprescindibles para garantizar el goce efectivo de los derechos de todos".

Como no será difícil advertir, el proyecto de ley archivado en 2016 se basa literalmente en esta sentencia cuando, atendiendo a lo dispuesto en el punto 8 de la misma, proscribe la asunción por parte de empresas participadas con capital extranjero de las actividades de vigilancia y seguridad humana (que pueden implicar el manejo de armas y otros elementos potencialmente dañinos como los canidos) y de la formación y la capacitación en seguridad privada. A su vez, va más allá que la sentencia y segrega un conjunto de actividades que sí estima aptas para ser asumidas por empresas que no sean puramente nacionales.

Atendiendo al razonamiento de la Corte Constitucional, esta diferenciación solo sería posible si estimamos que dichas actividades no están estrechamente relacionadas con el que hemos denominado núcleo esencial de la seguridad, que no participan esencialmente en la garantía de las condiciones que permiten el pleno ejercicio de los derechos y libertades fundamentales a todos los ciudadanos.

Es este el punto que creemos determinante en esta materia: Colombia, a través de sus normas y de la jurisprudencia de la Corte Constitucional ${ }^{36}$ no reconoce a la seguridad privada una naturaleza distinta de la pública; no asume que, además de la provisión del servicio público por parte de actores privados, puede suponer una actividad económica que produce bienes de consumo destinados a la eliminación o mitigación de riesgos generados por el desempeño de una actividad concreta,

especial que supone en la práctica la limitación de algunos de sus derechos y libertades, y sus procesos formativos se caracterizan, también, por implicar un aprendizaje en actitudes y valores (Vanaclocha Bellver, 2009, p. 46).

35 Materias a las que el legislador se ha enfrentado de forma específica y parcial con la elaboración y aprobación de la Ley 1920, de 12 de julio de 2018, por la cual se dictan disposiciones relacionadas con las cooperativas especializadas de vigilancia y seguridad privada y se busca mejorar las condiciones en las que el personal operativo de vigilancia y seguridad privada presta el servicio de vigilancia y seguridad privada. Ley del vigilante.

36 Acudimos a la jurisprudencia de la Corte Constitucional porque es la que, en un número estimable de sentencias (C 572 de 1997, C 199 de 2001, C 760 de 2002, C 995 de 2004 y C 123 de 2011), establece que la seguridad privada es considerada parte integrante de la seguridad pública y porque, como nos recuerda Gil Barrera (2017, p. 31), en Colombia la jurisprudencia es considerada fuente vinculante de derecho. 
pero que no tienen incidencia directa en la garantía de la seguridad común. De igual forma, al catalogar la seguridad como servicio público, no establece que precisamente ese núcleo esencial al que hemos hecho referencia -la garantía del pleno ejercicio de los derechos y libertades fundamentales- no puede ser considerada sino como una función propia del Estado, una potestad derivada de la soberanía, que implica ejercicio de autoridad y que, por lo tanto, es indelegable y debe ser asumida en exclusiva por parte de la Fuerza Pública.

La Corte Constitucional no reflexiona, como sí hace Ridaura Martínez (2015), acerca de la distinción entre los conceptos de servicio público y de función propia del Estado. No advierte, por lo tanto, que la noción de servicio público implica "la asunción de una actividad del sector privado por parte del público, en atención a su consideración de servicio esencial" (Ridaura, 2015, p.30), y que -como indica Martín Rebollo (1982) -, al referirse exclusivamente a ella, estaría asumiendo que la seguridad (al ser considerada un servicio público) es un tipo de actividad originariamente prestado por la iniciativa privada que se sujeta al Derecho Público mediante la técnica del Servicio público. No toma en consideración que aquellos ámbitos que implican una función de soberanía que queda reservada en exclusiva a la Administración pública -y que son, por lo tanto, indelegables- constituyen funciones propias del Estado.

Llama la atención el hecho de que, a pesar de no haberse realizado este esfuerzo de delimitación conceptual y de atribución de las categorías adecuadas en función de su respectiva naturaleza, la Corte Constitucional sí parece querer defender un grupo de funciones específicas y exclusivas del Estado al dejar claro en la sentencia C 525 de 1995 que solo podrán ser desempeñadas por la Fuerza Pública y que no serán, en ningún caso, asumidas por los operadores privados.

Esto se explica por medio del manejo de posiciones de raíz italiana que, como nos recuerda Montaña Plata (2002), conciben los servicios públicos como concreta expresión de las obligaciones que la Constitución impone al poder estatal, de tal forma que, por distinta vía, la resolución de la Corte Constitucional colombiana determina que la delegación que estima posible tiene un alcance limitado.

Para enfrentar la cuestión proponemos el ejemplo de cómo ha sido resuelta en Europa una controversia muy semejante.

En este caso ha sido el Tribunal de Justicia de la Unión Europea el que ha determinado que la excepción prevista en el apartado 1 del artículo 46 de la Constitución Europea, "que autoriza a los Estados miembros a mantener regímenes especiales para los extranjeros, que estén justificados por razones de seguridad pública" (Ridaura, 2015, p.63) no es aplicable a las normas generales sobre empresas de seguridad privada. 
El caso se planteó con respecto a España por la presencia en la Ley de Seguridad Privada ${ }^{37}$ y en el Reglamento de Seguridad Privada ${ }^{38}$ de disposiciones encaminadas a otorgar las concesiones de licencias de funcionamiento a las empresas de nacionalidad española y las habilitaciones para trabajar como personal de seguridad privada únicamente a los nacionales españoles. Similar fue el caso de Italia que, a semejanza de España, justificaba la exigencia de la nacionalidad italiana en la comprensión de la seguridad privada como ejercicio de poder público.

No lo entiende así el Tribunal al fallar reiteradamente que "las actividades de seguridad privada no participan directa y específicamente en el ejercicio del poder público" (Ridaura, 2015, p.63) al tiempo que señala que "en las misiones de vigilancia y protección sobre la base de relaciones jurídico-privadas, las empresas y el personal de seguridad no están investidos de poderes coercitivos" (Ridaura, 2015, p.64).

Por lo tanto, desde una perspectiva netamente jurídica, la proscripción de la participación extranjera en el sector solo sería defendible si se atribuye a la seguridad privada una naturaleza según la cual debe ser considerada exclusivamente como parte esencial del núcleo de la seguridad pública, lo cual, además de llevarnos al cuestionamiento acerca de si es posible la delegación en operadores privados de funciones propias de la soberanía estatal, implicaría una regulación coherente que obligaría considerar si todas las actividades actualmente encomendadas a los operados privados inciden de manera esencial en la seguridad pública y a definir adecuadamente la relación entre operadores públicos y privados, así como las competencias y la formación de estos últimos.

\section{- El aspecto económico.}

Aunque no sea este el ámbito de especialización de la autora, no podemos dejar pasar por alto la dimensión económica de esta cuestión, puesto que es en esta donde encontramos los más firmes argumentos en contra de la participación extranjera.

Puesta de manifiesto por los representantes gremiales, conecta con una eventual necesidad de protección de la empresa nacional basada en la afectación que a la leal competencia puede suponer la admisión de actores que van a desempeñarse en el mercado en desigualdad de condiciones. ${ }^{39}$

37 Ley 23/1992, de 30 de julio de Seguridad Privada.

38 Real Decreto 2364/1994, de 9 de diciembre.

39 El Sr. Medina Ovalle (comunicación personal, 20 de junio, 2017), representante de ANDEVIP, estima que las empresas multinacionales tienen la capacidad de introducir fuertes distorsiones al poder ofrecer, en calidad de valor agregado, elementos que para ellos tienen muy bajo coste (cita expresamente la posibilidad de las multinacionales de aportar tecnología procedente de sus matrices que ha sido retirada allí y que no tienen sino una repercusión exclusivamente positiva en sus balances contables).

Por su parte, El Mayor (r) Germán Duarte (comunicación personal, 21 de junio, 2017) alude al tamaño del mercado (al que considera pequeño) para señalar que la inversión extranjera no debe permitirse siempre y cuando se pre- 
Por su parte, la Sra. Borredá (Directora General de la editorial propietaria de las cabeceras Seguritecnia y Segurilatam) (comunicación personal, 22 de noviembre, 2016), argumentando con base en el caso español, advierte del peligro que para el sector puede suponer la cooptación y preeminencia por parte de fondos de inversión genéricos no controlados por especialistas en el ámbito de la seguridad. Estima que éstos persiguen exclusivamente rendimientos económicos y no priman la excelencia en la prestación de los servicios. Lo que puede traducirse en una pérdida de calidad que llegue a afectar negativamente a la reputación del sector.

En este mismo plano económico se advierte la necesidad de acudir a la perspectiva que ofrecen los Tratados de Libre Comercio que tiene suscritos Colombia ${ }^{40}$, y concretamente, a revisar en éstos los acuerdos de reciprocidad a los que se han llegado con las respectivas contrapartes. Si en estos países que han llegado a un acuerdo comercial con Colombia, se permite que haya inversión extranjera en el sector de la seguridad privada.

Independientemente del resultado que ofreciera el estudio propuesto, lo cierto es que Colombia cuenta con la opción de blindar en sus tratados de libre comercio a un determinado sector por considerarlo de interés relevante para la nación. Podría hacerlo con la seguridad privada.

Sin embargo, opinamos, no podría anclar firmemente su decisión en la argumentación jurídica tradicionalmente utilizada. Puesto que, como hemos desarrollado en el apartado anterior, la estimamos cuestionable.

Debería acudir a argumentos económicos y, al parecer, los aquí expuestos no serían compatibles con la política general de un ejecutivo interesado en fomentar y facilitar la recepción de capitales e inversiones extranjeras. ${ }^{41}$

\section{LOS RETOS.}

Elementos que deben ser tenidos en consideración para la configuración de un nuevo marco regulador

tenda preservar el carácter democrático del sector. Estima que la libre entrada de capital extranjero propiciaría una concentración empresarial que impediría crecer a las empresas colombianas que ya no gozan de un gran tamaño, lo que supondría -en su opinión- hacerles competir en situación de desigualdad.

40 Advertida por el Sr. Juan Carlos Medina Ovalle (Director Ejecutivo ANDEVIP) (comunicación personal, 20 de junio, 2017).

41 Al menos así lo indica la postura del gobierno de Juan Manuel Santos que, cuando un proyecto de ley que incluía una delimitada prohibición estaba próximo a ser aprobado, actuó para impedirlo; motivado, entre otras razones, porque este cierre sectorial contradecía su política económica de captación de inversiones extranjeras. 
Nuestra propuesta sugiere que el legislador, una vez adoptadas las posturas y tomadas las decisiones precisas para superar los obstáculos identificados, se defina respecto a aquellas materias o elementos consustanciales a la finalidad de emitir una ley generalista, reguladora del total de materias que configuran el sector, y dotada de coherencia y sistemática a lo largo de todos sus títulos.

El legislador debe reflexionar acerca de la propia concepción de la seguridad privada (de su naturaleza), así como la importancia que tiene el modo según el cual se entiende el papel preventivo que se le atribuye, además de atender a las advertencias de los profesionales con respecto a aquello que debe ser enfrentado para lograr la consecución de un sector fuerte y saneado: la lucha contra la informalidad y el intrusismo profesional. (Superintendente de Vigilancia y Seguridad Privada desde abril de 2017).Privada de mayo de 2015 a febrero de 2017) y cios a los

\section{- La prevención en el ámbito de la seguridad privada.}

La regulación vigente insiste en el papel preventivo que las actividades y servicios de seguridad privada deben desempeñar. Pretende el promotor de la norma que esta prevención suponga un aporte efectivo a la seguridad general de la población.

Por nuestra parte, estimamos que las capacidades que reconoce a los operadores privados limitan su margen de actuación a la atención de los efectos de las amenazas y no a sus causas, lo que determina que su papel no sea realmente preventivo, sino que se desempeñe como un mero elemento disuasorio de la comisión de delitos e infracciones.

La normativa que actualmente rige al sector identifica la prevención con la disuasión y la obstaculización del delito o la conducta asocial, olvidando las enseñanzas que nos aporta la ciencia criminológica cuando nos advierte que prevenir el delito es algo más, y también algo distinto, que dificultar su comisión. Ignorando que la prevención no puede desligarse de la génesis del fenómeno criminal y que reclama una intervención positiva que neutralice sus causas. Causas que la intervención de la seguridad privada, a través de la disuasión y obstaculización del delito, deja intactas (García-Pablos de Molina, 2005).

La argumentación precedente nos lleva a cuestionar la posibilidad de que la seguridad privada, tal y como actualmente está configurada, pueda contribuir efectivamente a la seguridad colectiva.

Como recuerda el Profesor García- Pablos (2014); la seguridad privada no persigue la protección de intereses colectivos y, si bien la adopción de ciertas medidas en determinados espacios puede producir un impacto preventivo general -un efecto disuasorio general-, no podemos descartar que lo que generen sea un mero desplazamiento del riesgo. 
Citándolo textualmente: "Quizás solo cabe por tanto aspirar a que procure una prevención intensa en el orden clientelar y al menos difusa respecto a los demás ciudadanos" (García-Pablos de Molina, 2014, p.150).

El legislador debe, por lo tanto, cuestionarse si puede utilizar la seguridad privada como elemento coadyuvante en los planes de consecución de mayores niveles de seguridad colectiva. Atribuirle un propósito preventivo implicaría dotar a los operadores privados de facultades que les permitieran colaborar con la Fuerza Pública al menos en la identificación y focalización de las causas de la generación del fenómeno criminal que se pretende combatir. Esto implicaría contar con personal del ámbito privado (con cargos y figuras profesionales específicos y dentro de los cuerpos de mando intermedio y dirección) debidamente formado y capacitado para entablar un tipo de relación con los agentes públicos que vaya más allá del mero suministro acrítico de información.

Pero también tiene la opción de contentarse con otorgarle una misión meramente disuasoria asumiendo, por supuesto, que la contribución de la seguridad privada se limitará a incrementar en alguna medida la seguridad colectiva de los habitantes de la zona o territorio específico en el que esté ubicado el bien o los bienes objeto de su protección, teniendo en cuenta que los potenciales riesgos que se evitan en aquella pueden desplazarse a otras en las que la seguridad privada no tenga presencia, lo que, obviamente, empeoraría sus índices de seguridad.

- La naturaleza de la seguridad privada y su relación con la seguridad pública.

La reflexión anterior nos lleva a un punto al que, estimamos, el legislador debe prestar especial atención: la naturaleza que se atribuye al sector de la seguridad privada.

Y ello debido a la transcendencia que esta determinación tiene tanto para la configuración del modelo normativo del sector como para la definición de la relación que ha de establecerse entre la dimensión pública y la dimensión privada de la seguridad.

Asignar a la seguridad privada una naturaleza exclusivamente privada o considerarla parte integrante de la seguridad pública es lo que va a determinar (si se pretende que el marco regulador sea coherente) cuál será la contribución del sector a incrementar los índices de seguridad de todos los ciudadanos y, por lo tanto, cómo debe articularse su relación con la Fuerza Pública. También definir el marco de actividades que podrá asumir y cuáles le estarán vedadas, el ámbito de actuación en el que podrán desempeñar sus funciones y el perfil básico que habrán de tener los profesionales de la seguridad privada (lo que, a su vez, determinará cuál será la formación y capacitación que deben recibir). 
Sin expresarlo de este modo, algunos de los entrevistados han señalado esta necesidad de determinación al referir que el sector es mal entendido por parte de algunos colectivos que aún lo confunden con el ámbito público, identificándolo con la seguridad nacional. ${ }^{42}$ Mientras otros, por su parte, destacan la dimensión exclusivamente privada de la actividad, refiriendo la transcendencia creciente que la seguridad empresarial tiene para el sector, y señalan que la misión de ésta consiste básicamente en proveer al empresario de recursos securitarios que aseguren el éxito de su operación económica, la continuidad del negocio o la minimización de las pérdidas ${ }^{43}$.

No nos atreveríamos a sugerir al legislador colombiano cuál es la opción más adecuada para el país en la actualidad, puesto que esto exige la profundización en la situación de la seguridad global de Colombia, el estudio de la evolución del concepto de seguridad -entendida de manera integral-y la elección de un modelo de sector con efectiva capacidad para contribuir positivamente a la seguridad pública (con carácter genérico) que deberá ser adecuadamente adaptado a las condiciones del país. Pero sí insistimos en que esta ha de ser la cuestión primaria y prioritaria acerca de la que ha de adoptar una posición si su objetivo es emitir una regulación con coherencia interna y otorgar una finalidad bien definida al operador privado dentro de la concepción de la seguridad de todos los ciudadanos.

- El tratamiento de la informalidad y la lucha contra el intrusismo en el sector.

La propia Superintendencia de Vigilancia y Seguridad Privada reconoce la existencia de los graves problemas de informalidad ${ }^{44}$ que denuncian los profesionales ${ }^{45}$.

Por lo tanto, la definición de un nuevo marco normativo con el que lograr una adecuada configuración de la vigilancia y la seguridad privada en Colombia exige la articulación de efectivos mecanismos de lucha contra estas realidades.

Consideramos que la fórmula adecuada para enfrentar esta problemática desde el ámbito legislativo exige la combinación de tres tipos de estrategias:

42 Carvajal Villamizar, Gerente general y Country President deSecuritas Colombia (comunicación personal, 5 de junio, 2017). Mayorga Prieto (comunicación personal, 3 de mayo, 2017), aunque si comparte la interpretación de la Corte Constitucional que considera la seguridad es un servicio público que determina que la seguridad privada sólo será el resultado de la delegación estatal de ese servicio en manos de los particulares, defiende que pertenece a una órbita diferente a la seguridad y la defensa nacional.

43 Mayor (r) Duarte Vargas, Representante de ADESEC. Gerente de ASEPROTECO (comunicación personal, 21 de junio, 2017).

44 Entidad que estima que el porcentaje de incidencia está en torno a un 15\%. Su máximo responsable reconoce que no se disponen de cifras precisas, lo cual prevé solventar estableciendo convenios para efectuar cruces de información con instituciones como la Cámara de Comercio de Bogotá (Martínez Bravo, comunicación personal, 6 de julio, 2017).

45 Medina Ovalle (comunicación personal, 20 de junio, 2017), Director Ejecutivo de ANDEVIP, muestra su preocupación acerca de este particular al considerar la ilegalidad y el intrusismo profesional como problemas que constituyen un reto para el sector. Esta asociación estima que el volumen de empresas que prestan este tipo de servicios sin cumplir con lo dispuesto en la normativa vigente puede estar, incluso, entorno al 50\%. 
- La primera, consistente en la adecuada delimitación del ámbito competencial. Lo que se logrará a través de la inclusión en la ley de definiciones claras que contribuyan a la seguridad jurídica y a evitar espacios de sombra en los que se puedan desarrollar la actividad y oferta de profesionales que no estén habilitados o autorizados para ejercer estas labores ${ }^{46}$.

- La segunda, de carácter reactivo, que supone que sean concebidas como infracciones -que llevarán aparejada su correspondiente sanción- las conductas de empresas, trabajadores o usuarios que oferten, ejerzan o contraten actividades de seguridad privada sin cumplir con los requisitos exigidos en la ley ${ }^{47}$.

- Y una última, e imprescindible para lograr los objetivos de la segunda, destinada a orientar prioritariamente los trabajos del órgano de control en esta dirección, así como a fortalecer la competencia de este para asumir esta misión ${ }^{48}$.

Estimamos que la paulatina superación de esta problemática es esencial no solo desde un punto de vista estrictamente económico. La consecución de un sector empresarial de la seguridad privada cuya profesionalidad y garantía en la ejecución de la oferta que realiza no se vean empañadas por la afectación que a estos valores puede producir el intrusismo (por la posibilidad de que actúen en este mercado prestadores de servicios no debidamente capacitados) no solo aporta a la protección económica y reputacional de las empresas, sino que contribuye a la consolidación de un sector efectivamente capacitado para reportar a la seguridad común los beneficios que de él se esperan.

Respondidos los interrogantes que estos retos plantean, y adoptadas las decisiones básicas tomando en consideración las particularidades y especificidades nacionales, será el momento de aproximarse a las soluciones legislativas que países con los que se pueda establecer una conexión histórica, socioeconómica, geopo-

46 Una adecuada delimitación conceptual que, además de violaciones legales, impediría que en normas relativas a otros ámbitos incluyeran disposiciones cuyo desarrollo podría entrar en conflicto con las competencias reconocidas a las empresas de vigilancia y seguridad privada.

Así, sería improbable la generación de controversias como la generada por el Proyecto de Ley 131 de 2016 Cámara, relativo a la propiedad horizontal. Este proyecto incluye una disposición (la 50 B) que la asociación ANDEVIP estima que puede invadir las competencias exclusivas que la normativa actual otorga a los vigilantes de seguridad respecto a la guardia y protección de conjuntos residenciales y sus moradores. Consideran que la regulación del servicio de conserjería que propone el proyecto implicaría por parte de los conserjes la asunción de funciones propias de la seguridad privada sin el correspondiente sometimiento a su regulación (Oscar Sánchez León, 2017).

47 Esta labor ha sido asumida por el legislador al introducir en el Proyecto de Ley 195/2016 C artículos como el 108 (sanciones por contratación de servicios ilegales) o el 110 (medidas en contra de prestadores ilegales de los servicios).

48 Van en esta dirección las propuestas que incluye el Proyecto de Ley 195/2016 C consistentes en la creación de un Registro Único destinado a mejorar las facultades de control de la Superintendencia y la asunción por parte de ésta de las funciones de policial judicial (86.13). 
lítica o de cultura jurídica ${ }^{49}$ han articulado para regular los diferentes aspectos que condicionan la configuración y el funcionamiento de su seguridad privada. Establecidas las bases más adecuadas a la realidad de Colombia, el análisis de las normas foráneas permitirá identificar cuáles de los recursos que proponen son coherentes con las líneas básicas trazadas por el legislador colombiano y pueden contribuir al establecimiento de un sector bien definido y con capacidad para cumplir con los objetivos que se le hayan atribuido.

\section{Conclusiones}

Una vez advertidas las carencias y disfunciones que pueden tener su origen en la legislación vigente, identificados los motivos que justifican el propósito de modificación de la normativa, señalados los factores de controversia que pueden impedir alcanzar un acuerdo y definidos los retos que deberá afrontar la elaboración de una nueva regulación para el sector de la seguridad privada en Colombia, animamos al legislador a no olvidar la relevancia que, para el adecuado funcionamiento de un sector tiene la configuración de un marco legal estructurado y coherente permita al menos evitar que sea la propia regulación la que genere o contribuya a las disfunciones que la práctica irá evidenciando.

Una arquitectura jurídica cimentada sobre una ley que diseñe y defina un modelo adecuado a la naturaleza atribuida a la actividad ${ }^{50} \mathrm{y}$ desarrollada por un reglamento que detalle los aspectos concretos del marco general establecido en la misma, que configure los elementos que necesita el sector para actuar de modo efectivo y que constituya una entidad jerarquizada que, de modo claro y preciso, regule el sector desde lo general a lo concreto.

49 Estimamos que no resultará sencillo encontrar esos nexos en la región. El informe que Fedesarrollo y Fedeseguridad dedican a la seguridad privada destaca en su aproximación al sector en América Latina que es difícil realizar una caracterización a causa de las discrepancias que se dan respecto al tamaño de los mercados, el número de empresas constituidas, la participación en producto interior bruto y, sobre todo, a causa de las enormes bolsas de informalidad (Fedesarrollo, 2018, pág. 15). Sin embargo, si que será posible tomar como referencia disposiciones adoptadas por las legislaciones vecinas que desarrollan en mayor medida apartados como el relativo a la obtención y registro de las licencias (y entre los que destacan las normativas de Costa Rica, el Salvador o Guatemala) y, con carácter genérico, los ordenamientos dedicados a la seguridad privada en Perú, Costa Rica, Guatemala, Bolivia y Uruguay que se destacan -junto con el Colombia- por contener los esfuerzos legislativos más acordes a lo contenido en el Proyecto de Convención sobre las Empresas Militares y de Seguridad Privada impulsado por las Naciones Unidas (UNLIREC, 2011).

50 Y que habrá de incluir necesariamente la determinación del papel que habrá de cumplir con respecto a la seguridad pública, así como el tipo de relación que mantendrá con sus operadores, las definiciones que aclaren términos esenciales, la fijación del ámbito material y la finalidad, la delimitación de las actividades consideradas propias, el catálogo de los principios rectores, la regulación del órgano de control, la definición de los actores y de las profesiones de seguridad privada (figuras y categorías profesionales y funciones), los requisitos de accesos a la profesión y la formación requerida, la descripción de los tipos de servicios, instrumentos, medios y medidas de seguridad admitidos, las medidas de control de la actividad, el diseño del sistema de capacitación y el régimen disciplinario y sancionador. 
Una legislación que configure un modelo normativo acorde con la concepción de seguridad asumida por Colombia y que permita, a través de la coherencia de todas sus disposiciones, la consecución de un sector profesional reputado con capacidad efectiva para contribuir a la seguridad común de todos los ciudadanos y coadyuvar al desarrollo económico de la nación.

\section{Referencias}

Angarita Cañas, P. E. (2010). Seguridad y Derechos Humanos. Las políticas de seguridad en Colombia, 2002-2008. (Tesis inédita de doctorado en Derecho), Universidad Pablo de Olavide, Sevilla.

Ávila, A. \& Londoño, J. E. (2017). Seguridad y Justicia en tiempos de paz. Bogotá: Debate Penguin Random House Grupo Editorial.

García-Pablos de Molina, A. (2005). Criminología. Una introducción a sus fundamentos teóricos. Valencia: Tirant Lo Blanch.

García- Pablos de Molina, A. (2014). El proceso de privatización de la seguridad. En Estudos de Direito Penal, Processual e Criminología em Homenagem ao Prof. Dr. Kurt Madlener (pp.139-152), Brasilia: Justica Federal.

Gil Barrera, R. (2017). Las fuentes del derecho en Colombia y criterios auxiliares de la actividad judicial. Medellín: Sello editorial Universidad de Medellín.

González González, F. E. (2014). Poder y Violencia en Colombia. Bogotá: Colección Territorio, Poder y Conflicto, Odecofi-Cinep (quinta reimpresión: septiembre 2016).

Martín Rebollo, L. (1982). De nuevo sobre el Servicio Público: planteamientos ideológicos y funcionalidad técnica. Revista de Administración Pública, núms.100-102.

Montaña Plata, A. (2002). El concepto de servicio público en el derecho administrativo. Bogotá: Universidad Externado de Colombia.

Ridaura Martínez, Ma J. (2015). Seguridad Privada y Derechos Fundamentales. La nueva Ley 5/2014, de 4 de abril, de Seguridad Privada. Valencia: Tirant Lo Blanch.

Rincón Morera, A. (2018). Abordajes teóricos sobre la relación entre seguridad ciudadana y violencia urbana en Colombia: una lectura crítica. URVIO, Revista Latinoamericana de Estudios de Seguridad, No 22, pp. 86-100. DOI: https://doi. org/10.17141/urvio.22.2018.3149

Rodríguez, L. (2017). Estructura del poder público en Colombia. Bogotá: Editorial Temis.

Sánchez León, 0. (2017). Representante a la Cámara, Enmienda articulado ponencia para el primer debate al Proyecto de Ley 131 de 2016 Cámara. Enmienda al texto propuesto para el primer debate del Proyecto de Ley 131 de 2016 Cámara "por medio del cual se crea el Registro Nacional de Unidades de Propiedad Horizontal y se modifica la Ley 675 de 2001". 
Santofimio Gamboa, J. O. (2017). Compendio de Derecho Administrativo. Bogotá: Universidad Externado de Colombia.

Sarabia Better, A. (2003). Reformas políticas en Colombia. Del Plebiscito de 1957 al Referendo del 2003. Bogotá: Norma Editorial.

Torrente Robles, D. (2016). Análisis de la seguridad privada. Barcelona: Editorial UOC.

Urrego Ortiz, F. \& Quinche Ramírez, M. F. (2008). Los decretos en el sistema normativo colombiano -Una política estatal de invención normativa, Universitas. Ucls., №116, pp. 53-83. ISSN: 0041-9060

Vanaclocha Bellver, F. J. (2009). Gobernanza en las políticas públicas de seguridad. Una nueva perspectiva sobre el lugar de la seguridad privada. En Seguridad Pública-Seguridad Privada. ¿Dilema o concurrencia?, Actas curso de verano. Madrid: Publicaciones de la Fundación Policía Española, Colección Estudios de Seguridad.

\section{Documentos institucionales}

Cámara de Comercio de Bogotá. Caracterización de los servicios de vigilancia y seguridad privada en Bogotá, 2008. Observatorio de Seguridad de la Cámara de Comercio de Bogotá. Recuperado de https://www.supervigilancia.gov.co/ publicaciones/4284/observatorio-de-seguridad-en-bogota-caracterizacion-delos-servicios-de-vigilancia-y-seguridad-privada/

Centro Regional de las Naciones Unidas para la Paz, el Desarme y el Desarrollo en América Latina y el Caribe (UNLIREC). Control y regulación de las empresas de Seguridad Privada en América Latina y el Caribe: un análisis comparativo, 2011. Naciones Unidas. Recuperado de http://www.unlirec.org/documents/ResejecPrivada_Oct\%202016.pdf

Federal Department of Foreing Affairs (FDFA), DCAF. Guía legislativa para Estados sobre la Regulación de las Empresas Militares y de Seguridad Privada, 2016. Ginebra. Recuperado de https://www.ppps.dcaf.ch/sites/default/files/uploads/LegislativeGuidance-Tool-ES.pdf

Fedesarrollo, Fedeseguridad. El sector de seguridad y vigilancia privada: evolución reciente y principales retos laborales, regulatorios y de supervisión, 2018. Cuadernos Fedesarrollo 65, julio, 2018.

Gobierno de Colombia. Acuerdo final para la terminación del conflicto y la construcción de una paz estable y duradera, 2016. Bogotá. Recuperado de http://www. altocomisionadoparalapaz.gov.co/procesos-y-conversaciones/Documentos\%20 compartidos/24-11-2016NuevoAcuerdoFinal.pdf

Programa de las Naciones Unidas para el Desarrollo (PNUD). Informe Regional de Desarrollo Humano 2013-2014. Seguridad Ciudadana con rostro humano: diagnóstico y propuestas para América Latina. Producción editorial PNUD. Recuperado de http://www. undp.org/content/dam/rblac/img/IDH/IDH-AL\%20Informe\%20completo.pdf 
Superintendencia de Vigilancia y Seguridad Privada. Borrador-propuesta de modificación del Decreto Ley 356 de 1994, febrero de 2017.

\section{Legislación}

Colombia. Constitución Política de Colombia, (CPC). 4 de julio de 1991.

Colombia. Congreso de la República. (1993). Ley 61. Por la cual se reviste al Presidente de la República de facultades extraordinarias para dictar normas sobre armas, municiones y explosivos, y para reglamentar la vigilancia y la seguridad privada. Diario Oficial. Bogotá, D.C., 1993. no. 40.987.

Colombia. Congreso de la República. (1993). Ley 62. . Por la cual se expiden normas sobre la Policía Nacional, se crea un establecimiento público de seguridad social y Bienestar para la Policía Nacional, se crea la Superintendencia de Vigilancia y Seguridad Privada y se reviste de facultades extraordinarias al Presidente de la República. Diario Oficial. Bogotá, D.C., 1993. no. 40.987.

Colombia. Congreso de la República. (12, julio, 2018). Ley 1920. Por la cual se dictan disposiciones relacionadas con las cooperativas especializadas de vigilancia y seguridad privada y se busca mejorar las condiciones en las que el personal operativo de vigilancia y seguridad privada presta el servicio de vigilancia y seguridad privada. Ley del Vigilante. Diario Oficial. Bogotá, D.C., 2018. no. 50.652 p. 13-15.

España. Jefatura del Estado. (30 de julio, 1992). Ley 23. De Seguridad Privada. Boletín Oficial del Estado. Madrid, 1992. no. 186, p. 27116-27122.

España. Ministerio de Justicia e Interior. (1994). Real Decreto 2364. Por el que se aprueba el Reglamento de Seguridad Privada. Boletín Oficial del Estado. Madrid, 1994. no. 8, p. 779-815.

Colombia. Ministerio de Defensa Nacional. (1990). Decreto 848. Por el cual se expide el Estatuto de vigilancia privada. Diario Oficial. Bogotá, D.C., 1990. No. 39.315.

Colombia. Ministerio de Defensa Nacional. (1993). Decreto 2203. Por el que se desarrollan la estructura orgánica y las funciones de la policía nacional. Diario Oficial. Bogotá, D.C., 1993. no. 41.104.

Colombia. Ministerio de Defensa Nacional. (1993). Decreto 2453. Por el cual se determina la estructura orgánica, objetivos, funciones y régimen de sanciones de la Superintendencia de Vigilancia y Seguridad Privada. Diario Oficial. Bogotá, D.C., 1993. no. 41.128.

Colombia. Ministerio de defensa nacional. (1993). Decreto 2535. Por el cual se expiden normas sobre armas, municiones y explosivos. Diario Oficial. Bogotá, D.C., 1993. no. 41.142 .

Colombia. Ministerio de Defensa Nacional. (1994). Decreto 356. Por el cual se expide el Estatuto de Vigilancia y Seguridad Privada. Diario Oficial. Bogotá, D.C., 1994. no. 41.220 . 
Colombia. Ministerio de Defensa Nacional. (2001). Decreto 2187. Por el cual se reglamenta el Estatuto de Vigilancia y Seguridad Privada contenido en el Decreto-ley 356 de 11 de febrero de 1994. Diario Oficial. Bogotá, D.C., 2001. no. 44.598.

Colombia. Superintendencia de Vigilancia y Seguridad Privada. (2006). Resolución 2852. Por la cual se unifica el Régimen de Vigilancia y Seguridad Privada. Diario Oficial. Bogotá, D.C., 2006. no. 46.382.

Colombia. Superintendencia de Vigilancia y Seguridad Privada. (2010). Resolución 2946. Por la cual se modifica el Régimen de Control, Inspección y Vigilancia en la Superintendencia de Vigilancia y Seguridad Privada. Diario Oficial. Bogotá, D.C., 2010. No. 47.700.

Colombia. Congreso de la República. (2016). Proyecto de Ley 195/2016 C. Por la cual se regula el sector de vigilancia y seguridad privada en Colombia y se dictan otras disposiciones.

\section{Jurisprudencia}

Colombia. Corte Constitucional, Sentencia SU 476 (1997)

Colombia. Corte Constitucional, Sentencia C-572 (1997)

Colombia. Corte Constitucional, Sentencia C-199 (2001)

Colombia. Corte Constitucional, Sentencia C-760 (2002)

Colombia. Corte Constitucional, Sentencia C-125 (2003)

Colombia. Corte Constitucional, Sentencia C-1053 (2003)

Colombia. Corte Constitucional, Sentencia C-995 (2004)

Colombia. Corte Constitucional, Sentencia C-123 (2011)

Colombia. Corte Constitucional, Sentencia C-160 (2017)

España. Tribunal de Justicia de la Unión Europea. Sentencia Comisión (15 de marzo de 1998).

España. Tribunal de Justicia de la Unión Europea. Sentencia Comisión (29 de octubre de 1998).

Bélgica. Tribunal de Justicia de la Unión Europea. Sentencia Comisión ( 9 de marzo de 2000).

Entrevistas (comunicaciones personales con la autora).

Borredá, A., Directora General de la Editorial Borrmart, 22 de noviembre de 2016, Madrid.

Carvajal Villamizar, S., Gerente General y Country President de SECURITAS Colombia, 5 de junio de 2017, Bogotá. 
Duarte Vargas, G. Mayor (r), Representante de ADESEC. Gerente AESEPROTECO, 21 de junio de 2017, Bogotá.

Gaitán Gómez, I. M., Coordinador Especialización Alta Gerencia en Seguridad y Defensa. Universidad Militar Nueva Granada, 9 de mayo de 2017, Bogotá.

González Rodríguez, J. C., Coordinador Especialización en Administración de la Seguridad. Universidad Militar Nueva Granada, 9 de mayo de 2017, Bogotá.

Jiménez Cuello, A., Asesor de Seguridad ciudadana del Senador Iván Cepeda, 6 de junio de 2017, Bogotá.

La Rotta Bautista, L. E. Coronel (r), Gerente General de ISVI Ltda. Director General del Instituto de Seguridad Metis Sicurex, 21 de julio de 2017, Bogotá.

Macías Tolosa, A., Investigador y docente CIPE- Línea de investigación Conflicto, Paz y Seguridad. Universidad Externado de Colombia, 11 de mayo de 2017, Bogotá.

Martínez Bravo, F., Superintendente de Vigilancia y Seguridad Privada desde abril de 2017, 6 de julio de 2017, Bogotá.

Mayorga Prieto, C. A., Superintendente de Vigilancia y Seguridad Privada de mayo de 2015 a febrero de 2017, 3 de mayo de 2017, Bogotá.

Medina Ovalle, J. C., Director Ejecutivo ANDEVIP, 20 de junio de 2017, Bogotá.

Vásquez Higuera, J. C., Superintendente de Vigilancia y Seguridad Privada en el período 1998-2002. Director Gestión de Seguridad Ciudadana y Empresarial. Vicepresidencia de articulación Público- Privada. Cámara de Comercio de Bogotá, 5 de junio de 2017, Bogotá. 